\title{
Giúp "Thanh niên Sáng tạo Khởi nghiệp” làm giầu chính đáng
}

\author{
Thánh Gióng Portal
}

April 11, 2014

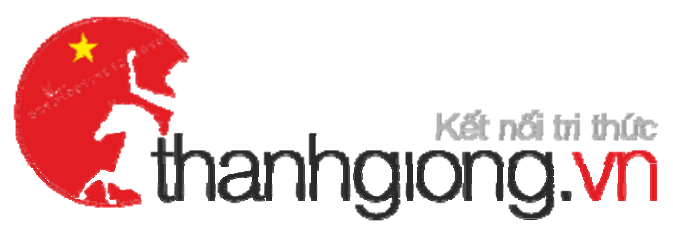

Trung ương Hội Liên hiệp Thanh niên Việt Nam

https://thanhgiong.vn/giup-thanh-nien-sang-tao-khoi-nghiep-lam-giauchinh-dang-18821.html 


\title{
Giúp "Thanh niên Sáng tạo Khởi nghiệp" làm giầu chính đáng
}

\author{
(CTG) Phát hiện, bồi dưỡng, tạo điều kiện chắp cánh cho nhũng \\ thanh niên dám nghĩ, dám làm, lập thẩn, lập nghiệp làm giầu \\ chính đáng trên quê hương.
}

Chiều ngày 11/4, tại Hà Nội, Bí thư Trung ương Đoàn Nguyễn Long Hải và đại diện lãnh đạo Trung ương Hội LHTN Việt Nam đã có buổi gặp gỡ, trao đổi với các chuyên gia kinh tế về chương trình khởi nghiệp cho thanh niên, giai đoạn $2014-2017$.

Tham dự buổi gặp gỡ, trao đổi có PGS.TS Trần Đình Thiên - Viện trưởng Viện Kinh tế Việt Nam; TS Vương Quân Hoàng - Chủ tịch Hội đồng quản trị Công ty DHVP Research \& Congsultancy và đồng chí Bạch Ngọc Chiến - nguyên Trưởng Ban biên tập VTV4 Đài truyền hình Việt Nam.

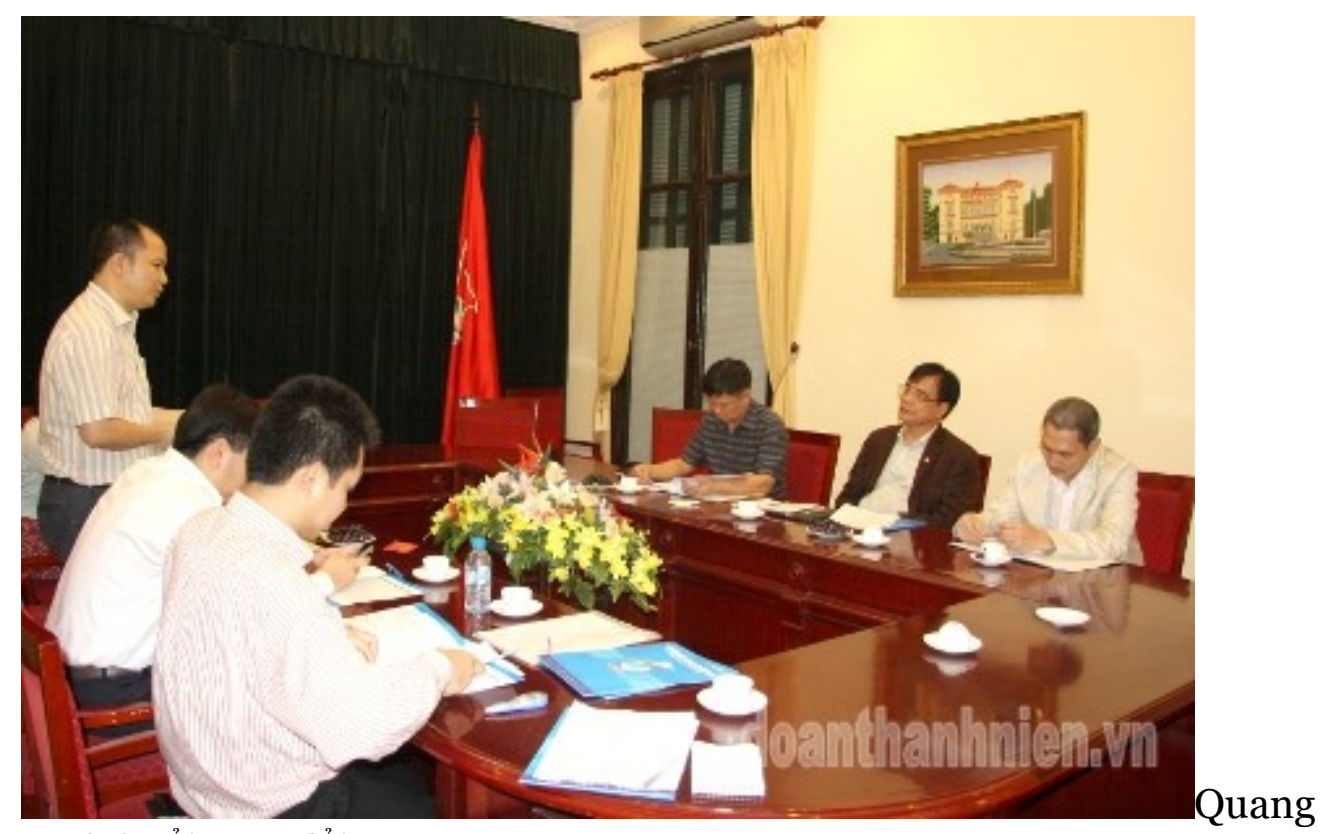

cảnh buổi trao đổi.

Tại buổi gặp gỡ, Trung ương Hội LHTN Việt Nam đã trao đổi, chia sẻ với các chuyên gia về những tâm, nguyện vọng của nhiều bạn trẻ hiện nay có mong muốn được vươn lên lập nghiệp, làm giàu chính đáng ngay tại địa phương; trao đổi về định hướng của Hội LHTN Việt Nam trong việc xây dựng và phát triển bền vững hệ thống CLB thanh niên khởi nghiệp về mô hình CLB; cách thức đào tạo khởi nghiệp; hình thức giao lưu và trao đổi kinh nghiệm; tư vấn kỹ thuật và bảo trở khởi nghiệp. Định hướng thành lập Hội đồng cố vấn của chương trình khởi nghiệp và đặc biệt là chương trình "Thanh niên Sáng tạo Khởi nghiệp" năm 2014 và dự kiến chương trình "Thanh niên Sáng tạo Khởi nghiệp" giai đoạn 2014 - 2017...

Nói về khơi nghiệp của thanh niên, TS Trần Đình Thiên cho rằng, vói những người khởi nghiệp hãy giúp cho họ tạo ra những năng lực cơ bản để họ tạo ra lên sự nghiệp, đồng thời tạo ra không gian, môi trường để họ tạo ra năng lực thực tế. TS Trần Đình Thiên nhấn mạnh: “đối với thanh 
niên dạy cho họ hãy tích cực đầu tư mạo hiểm".

Theo TS Vương Quân Hoàng, cần chuẩn bị tốt nội dung hoạt động của các CLB thanh niên khởi nghiệp và tạo ra những bài tập thực tế gắn với những trường Đại học được chọn làm hạt nhân để tạo nên những vươn ươm thanh niên giúp họ khởi nghiệp.

Để giúp thanh niên khởi nghiệp, TS Hoàng đề xuất cần có một lộ trình về thanh niên khởi nghiệp và xây dựng cho được hình mẫu thanh niên khởi nghiệp để từ đó lan tỏa rộng khắp trong cả nước.

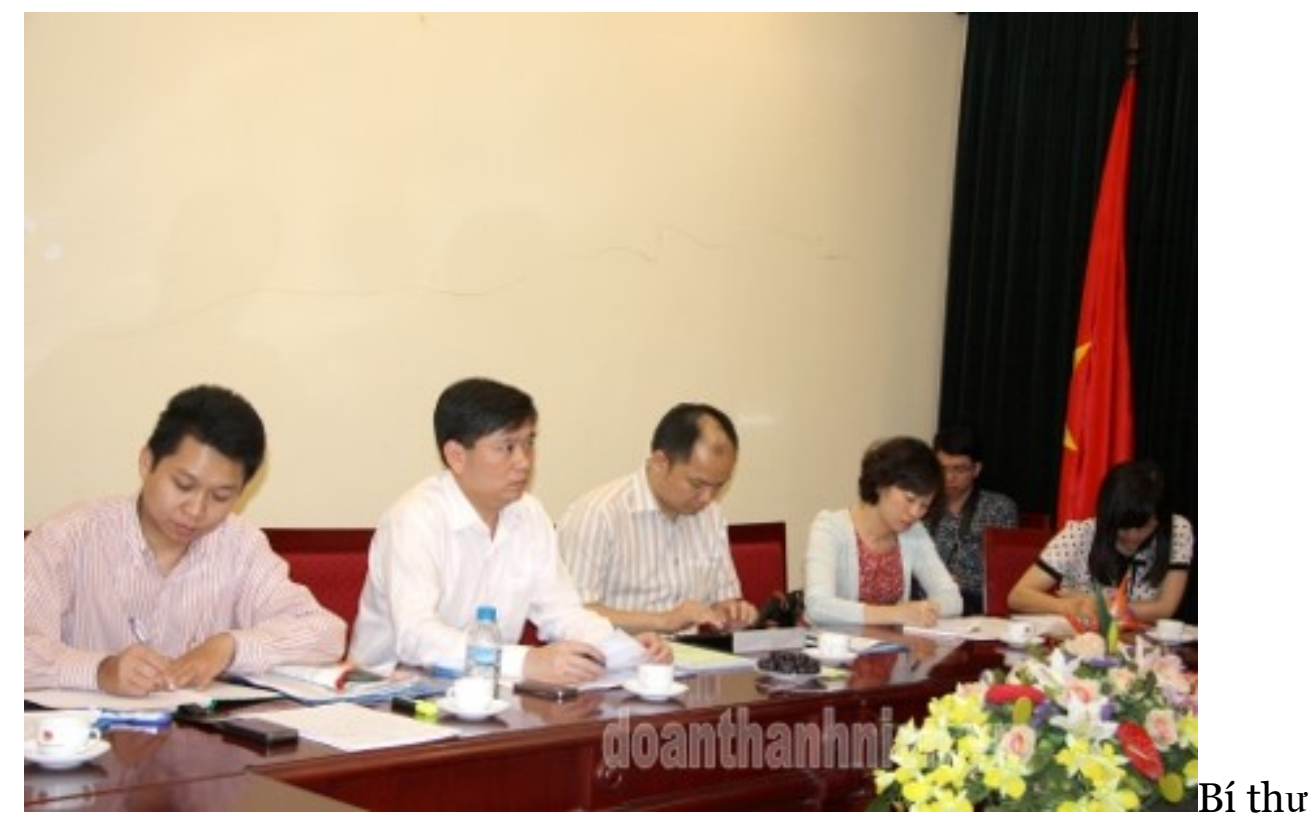

Trung ương Đoàn Nguyễn Long Hải (thứ hai, từ trái sang) trao đổi ý kiến với các chuyên gia.

Với những ý kiến của các chuyên gia, Bí thư Trung ương Đoàn Nguyễn Long Hải nêu ý kiến thời gian tới thành lập Hội đồng cố vấn chương trình "Thanh niên Sáng tạo Khởi nghiệp" và Hội LHTN Việt Nam cần xây dựng từ 3 đến 5 Trung tâm hỗ trợ thanh niên khởi nghiệp theo các vùng, miền lấy các CLB thanh niên khởi nghiệp làm vệ tinh cho các Trung tâm này.

Hy vọng với những định hướng của chương trình giúp "Thanh niên Sáng tạo Khởi nghiệp" trong thời gian tới được tổ chức sẽ là cơ hội cho nhiều bạn trẻ được lập thân, lập nghiệp làm giàu chính đáng, giải quyết được nhu cầu việc làm cho nhiều người lao động, góp phần xóa đói giảm nghèo, xây dựng quê hương, đất nước ngày càng giàu mạnh, văn minh, âm no, hạnh phúc. 


\section{Tài liệu tham khảo:}

[1] Vương Quân Hoàng. (2007). Văn minh làm giàu \& nguồn gốc của cải. Nxb Chính trị quốc gia, Hà Nội.

[2] Vuong Quan Hoang, \& Tran Tri Dung. (2009). The cultural dimensions of the Vietnamese private entrepreneurship. The IUP Journal of Entrepreneurship and Development, 6(3), 54-78. 